\title{
Investigation of aerosol indirect effects on monsoon clouds using ground-based measurements over a high-altitude site in Western Ghats
}

\author{
Vasudevan Anil Kumar, Govindan Pandithurai, Parakkatt Parambil Leena, Kundan K. Dani, Palani Murugavel, \\ Sunil M. Sonbawne, Rohit D. Patil, and Rajamma Sukumaran Maheskumar
}

Indian Institute of Tropical Meteorology, Pune, 411008, India

Correspondence to: Govindan Pandithurai (pandit@tropmet.res.in)

Received: 29 December 2015 - Published in Atmos. Chem. Phys. Discuss.: 19 January 2016

Revised: 6 June 2016 - Accepted: 7 June 2016 - Published: 12 July 2016

\begin{abstract}
The effect of aerosols on cloud droplet number concentration and droplet effective radius is investigated from ground-based measurements over a high-altitude site where clouds pass over the surface. First aerosol indirect effect (AIE) estimates were made using (i) relative changes in cloud droplet number concentration $\left(\mathrm{AIE}_{\mathrm{n}}\right)$ and (ii) relative changes in droplet effective radius $\left(\mathrm{AIE}_{\mathrm{s}}\right)$ with relative changes in aerosol for different cloud liquid water contents (LWCs). AIE estimates from two different methods reveal that there is systematic overestimation in $\mathrm{AIE}_{\mathrm{n}}$ as compared to that of $\mathrm{AIE}_{\mathrm{s}}$. Aerosol indirect effects $\left(\mathrm{AIE}_{\mathrm{n}}\right.$ and $\left.\mathrm{AIE}_{\mathrm{s}}\right)$ and dispersion effect $(\mathrm{DE})$ at different $\mathrm{LWC}$ regimes ranging from 0.05 to $0.50 \mathrm{~g} \mathrm{~m}^{-3}$ were estimated. The analysis demonstrates that there is overestimation of $\mathrm{AIE}_{\mathrm{n}}$ as compared to $\mathrm{AIE}_{\mathrm{s}}$, which is mainly due to DE. Aerosol effects on spectral dispersion in droplet size distribution play an important role in altering Twomey's cooling effect and thereby changes in climate. This study shows that the higher DE in the medium LWC regime offsets the AIE by $30 \%$.
\end{abstract}

\section{Introduction}

There exists a strong correlation between aerosol and cloud microphysics: more aerosols leads to many smaller cloud droplets for a fixed liquid water content, which increases the cloud optical thickness and cloud albedo (Twomey, 1974). This is termed aerosol indirect effect (AIE), which in turn cools the Earth's surface. But anthropogenic aerosols having complex chemical composition will broaden cloud droplet spectral width and reduce the AIE (Liu and Daum, 2002). Several theoretical and observational studies of aerosolcloud interaction and estimation of AIE on maritime as well as continental clouds have been conducted worldwide. However, the magnitude of this AIE still remains uncertain because of the complexity in the estimation (Menon et al., 2008).

In the estimation of $\mathrm{AIE}_{\mathrm{n}}$ in many numerical models, the effect of dispersion is not considered, but the field studies of the indirect aerosol effect show that polluted marine clouds and clouds of continental origin generally have both larger number concentration and a larger relative dispersion $(\varepsilon)$ of the droplet size distribution relative to clean marine clouds (Liu and Daum, 2002). Hudson and Yum (1997) reported that the spectral width $(\sigma)$ of cloud droplet spectra was greater with higher $N_{\text {ccn }}$ from the Atlantic Stratocumulus Transition Experiment (ASTEX) conducted in 1992. They also observed that this small $\sigma$ difference can be noticed if cloud parcels with droplets of same mean diameter were considered. Liu and Daum (2002) show the relation between relative dispersion of cloud droplet size distribution and number concentration of cloud droplets from 13 different experiments, of which 11 cases show higher relative dispersion with higher $N_{\text {ccn }}$, and a slight decrease in the other two.

Pandithurai et al. (2012) reported aerosol-cloud relationships and estimated AIE for warm continental cumuli over the Indian subcontinent using Cloud Aerosol Interactions and Precipitation Enhancement Experiment (CAIPEEX) aircraft campaign data sets and observed influence of higher cloud condensation nuclei $(\mathrm{CCN})$ concentration on cloud droplet dispersion as it significantly offsets AIE over continental 
clouds. They also indicated that the dispersion effect may be implicitly included in the estimation of AIEs derived using relative changes in cloud effective radius $\left(R_{\text {eff }}\right)$ with relative changes in aerosol concentration $\left(N_{\text {acc }}\right)$. Hudson and Noble (2013) reported that the increase in relative dispersion is largely due to decrease in droplet mean radius rather than increase in spectral width. However, Liu et al. (2013), Pandithurai et al. (2012), and the present study showed that the spectral width of droplet spectra shows increase if we consider a fixed mean droplet radius. Martins et al. (2009) showed that the increase in aerosol loading due to biomass burning aerosols decreases the spectral width and in turn enhances the Twomey cooling effect. These contrasting reports suggest that more work is needed on this topic.

Aerosol semi-direct effect also plays an important role as absorbing aerosols enhances the atmospheric heating due to absorption of solar radiation, which in turn changes the relative humidity and thereby inhibits cloud development and burns off the clouds (Huang et al., 2014). Since the percentage/fraction of absorbing aerosol at this site during study period (monsoon season) is much less compared to scattering type aerosol, which is detailed in Sect. 2, the semi-direct effect due to absorbing aerosol (e.g. BC) is comparatively much less. So the aerosol semi-direct effect is not dealt with in this study.

Thus in the present work aerosol effects on cloud microphysical properties from collocated simultaneous measurements over Mahabaleshwar, Western Ghats region in the Indian state of Maharashtra, have been studied. Detailed analysis of AIE and its offset due to dispersion effect (DE) at different cloud liquid water content (LWC) regimes are presented.

\section{Data used}

The recently set up High Altitude Cloud Physics Laboratory (HACPL) at Mahabaleshwar $\left(17.56^{\circ} \mathrm{N}, 73.4^{\circ} \mathrm{E}\right.$; $1348 \mathrm{~m}$ a.m.s.l.) has various ground-based instruments for observation of aerosol as well as clouds. The observatory is situated in the Western Ghats, wherein during monsoon season the temperature is varied between 17 and $23^{\circ} \mathrm{C}$ and relative humidity varied between 85 and $100 \%$ with an average rainfall of $500 \mathrm{~cm} \mathrm{yr}^{-1}$. It is also observed that the site is covered by warm continental clouds most of the time during the summer monsoon season. Interestingly, observation from laboratory has shown that the total aerosol concentration in the size range $(5 \mathrm{~nm}$ to $30 \mu \mathrm{m})$ varies from 100 to $25000 \mathrm{~cm}^{-3}$, and occasionally it reached up to 40000 particles $\mathrm{cm}^{-3}$ and $\mathrm{CCN}$ concentration from 400 to $20000 \mathrm{~cm}^{-3}$. The aerosol and $\mathrm{CCN}$ concentration measurement shows that the region experiences higher aerosol concentrations during monsoon season in spite of washout/scavenging due to precipitation (Leena et al., 2016). The chemical composition of submicron aerosols over this
Table 1. Data sampling dates/periods used in this study during which no precipitation was recorded.

\begin{tabular}{llcr}
\hline Date & $\begin{array}{l}\text { From } \\
\text { Indian standard time (IST) }\end{array}$ & $\begin{array}{r}\text { Total } \\
\text { (minutes) }\end{array}$ \\
\hline 06 Jun 2013 & $16: 07$ & $16: 40$ & 33 \\
11 Jun 2013 & $08: 38$ & $09: 13$ & 35 \\
12 Jun 2013 & $09: 10$ & $12: 37$ & 207 \\
23 Jun 2013 & $09: 54$ & $10: 59$ & 65 \\
15 Jul 2013 & $22: 35$ & $22: 51$ & 16 \\
25 Jul 2013 & $09: 53$ & $10: 37$ & 41 \\
07 Aug 2013 & $19: 51$ & $22: 40$ & 169 \\
16 Aug 2013 & $10: 04$ & $17: 19$ & 75 \\
18 Aug 2013 & $18: 02$ & $20: 39$ & 279 \\
& $21: 00$ & $23: 02$ & \\
19 Aug 2013 & $19: 58$ & $23: 01$ & 83 \\
20 Aug 2013 & $22: 04$ & $23: 31$ & 1190 \\
\hline Total & & & \\
\hline
\end{tabular}

site during monsoon season is found to be dominated by organics $(77 \%)$, sulfates $(14 \%)$, chlorides $(4 \%)$, and nitrates. Significant fraction of secondary organic aerosols could be formed from volatile organic compounds emitted from the wet vegetation. Also, the monsoon winds can bring a significant amount of coarse sea salt particles.

In this work, we have made an attempt to study the influence of aerosol on cloud microphysical properties and their relationship using data collected during 2013 monsoon season. We have related cloud microphysical properties such as cloud droplet number concentration (CDNC) and cloud droplet effective radius $\left(R_{\text {eff }}\right)$ to CCN concentration $\left(N_{\mathrm{ccn}}\right)$ measured simultaneously by using various ground-based instruments, and the details are described below. It is to be noted that, for the present study, data considered were explicitly for non-rainy conditions; cloud probes were operated only during non-rainy cloudy conditions, and the possibility of even small drizzles was eliminated by comparing the data with rain rates obtained from impact disdrometer. After scrutinizing the entire data set, about $20 \mathrm{~h}$ of data was considered for analysis, as detailed in Table 1.

\subsection{CCN counter}

The CCN counter, which is a continuous flow thermal gradient instrument (Roberts and Nenes, 2005) manufactured by Droplet Measurement Technologies (DMT Inc.), was used for $\mathrm{CCN}$ concentration measurement. It was configured to operate at a fixed supersaturation (SS) of $0.6 \%$ and sampling rate of $1 \mathrm{~Hz}$. This $\mathrm{CCN}$ counter has a thermal gradient diffusion chamber in which a supersaturated water vapour condition is created. This supersaturated water vapour condenses on the $\mathrm{CCN}$ in the sample air to form droplets. An optical particle counter (OPC), using side-scattering technology, counts and sizes the activated drops. 


\subsection{Cloud Combination Probe}

Cloud microphysical parameters were collected with a Cloud Combination Probe (CCP) from DMT Inc, which is a combination of cloud droplet probe (CDP) and a hot-wire liquid water content probe (HW-LWC). The CDP measures the cloud droplet size distribution (DSD) and concentration of droplet sizes from 3 to $50 \mu \mathrm{m}$, categorized into 30 channels. The CDP uses a laser to illuminate particles and forwardscatter their light. The detected scattered light is then used to size the particles. The intensity of the scattered light depends upon the size, composition, and shape of the particle. LWC was measured using the hot-wire probe and also estimated from CDP drop size distribution measurements. For calculating spectral dispersion in cloud droplet size distribution and to estimate AIE, cloud droplet mean radius $\left(r_{\mathrm{m}}\right)$, spectral width of DSD $(\sigma)$, and relative dispersion $(\varepsilon)$ were calculated from the data obtained from CDP. The mathematical definition of $r_{\mathrm{m}}, \sigma$, and $\varepsilon$ is as follows:

$r_{\mathrm{m}}=\frac{\sum_{i=1}^{n} N_{i} r_{i}}{N}$

$\sigma=\left[\frac{\sum_{i=1}^{n} N_{i}\left(r_{i}-r_{\mathrm{m}}\right)^{2}}{N}\right]^{1 / 2}$

$\varepsilon=\frac{\sigma}{r_{\mathrm{m}}}$

where $N_{i}$ is the droplet concentration within channel $i, r_{i}$ the midpoint radius for size channel $i$, and $N$ the total droplet concentration.

\section{Analysis procedure}

As per Twomey's hypothesis, cloud droplet number concentration increases and cloud droplet size decreases with an increase in aerosol concentration for a fixed liquid water path (LWP). AIE can be estimated by utilizing both cloud droplet number $\left(\mathrm{AIE}_{\mathrm{n}}\right)$ and droplet effective diameter $\left(\mathrm{AIE}_{\mathrm{s}}\right)($ Feingold et al., 2003) through the following expressions:

$$
\begin{aligned}
& \mathrm{AIE}_{\mathrm{n}}=\frac{1}{3} \frac{\Delta \log N_{\mathrm{c}}}{\Delta \log \alpha} \\
& \mathrm{AIE}_{\mathrm{s}}=-\frac{\Delta \log R_{\mathrm{eff}}}{\Delta \log \alpha},
\end{aligned}
$$

where $\Delta N_{\mathrm{c}}$ is the relative change in cloud droplet number concentration, $R_{\text {eff }}$ the cloud drop effective radius, and $\alpha$ is the aerosol or CCN concentration.

$R_{\text {eff }}$ in the above relation is the ratio between third and second moment of CDP-measured cloud droplet size distribution (Hansen and Travis, 1974). $R_{\text {eff }}$ is an important parameter in aerosol-cloud interaction studies and can be ex- pressed as

$R_{\mathrm{eff}}=\frac{\sum_{i=1}^{n} p_{i} r_{i}^{3}}{\sum_{i=1}^{n} p_{i} r_{i}^{2}}$,

where $n$ is the number of droplet sizing bins (30 bins for $\mathrm{CDP}), p_{i}$ is the particle count for bin $i$, and $r_{i}$ is the mean radius in micrometres of bin $i$. For $R_{\text {eff }}$ parameterization, climate models use a one-third power law which relates cloud liquid water content (LWC) and number concentration $\left(N_{\mathrm{c}}\right)$ (Slingo, 1990; Bower et al., 1994; Liu et al., 2006), and the same can be written as

$R_{\mathrm{eff}}=\beta\left[\frac{3 \mathrm{LWC}}{4 \pi \rho_{\mathrm{W}} N_{\mathrm{c}}}\right]^{\frac{1}{3}}$,

where $\rho_{\mathrm{w}}$ is the water density and $\beta$ is the effective radius ratio, which is a function of the spectral shape of the cloud droplet size distribution. Previous studies show that considering the dispersion effect is important for estimating AIE (Liu et al., 2008; Peng and Lohmann, 2013).

Liu and Daum $(2000,2002)$ put forward an expression corresponding to a gamma distribution to describe the $\beta$ dependence on spectral droplet size distribution, which is as follows

$\beta=\frac{\left[1+2 \varepsilon^{2}\right]^{2 / 3}}{\left[1+\varepsilon^{2}\right]^{1 / 3}}$,

where $\varepsilon$ is the relative dispersion of the droplet size distribution and can be defined as the ratio of the standard deviation to the mean radius of the droplet size distribution. Liu et al. (2008) studied the relation between $\beta$ and $\left(L / N_{\mathrm{c}}\right)$ (water per droplet or specific cloud water content) to avoid uncertainties in the existing $\beta(\varepsilon)-N_{\mathrm{c}}$ relation to explain the dispersion effect. The relation between $\beta$ and $\left(L / N_{\mathrm{c}}\right)$ can be expressed as

$\beta=\alpha_{\beta}\left(\frac{L}{N_{\mathrm{c}}}\right)^{-b_{\beta}}$,

where $\alpha_{\beta}$ is the intercept of the power law fit between $\beta$ and $L / N_{\mathrm{c}} ; b_{\beta}$ is the dispersion factor defined as the percentage of the offset in the Twomey cooling effect, due to the dispersion in the cloud droplet size distribution.

\section{Results and discussion}

To understand the interaction of aerosol with cloud microphysical parameters, cloud droplet number concentration (CDNC) and its effective radius (ED) against CCN concentration are plotted and displayed in Fig. 1. It can be noted from this figure that higher $\mathrm{CCN}$ causes a larger number 


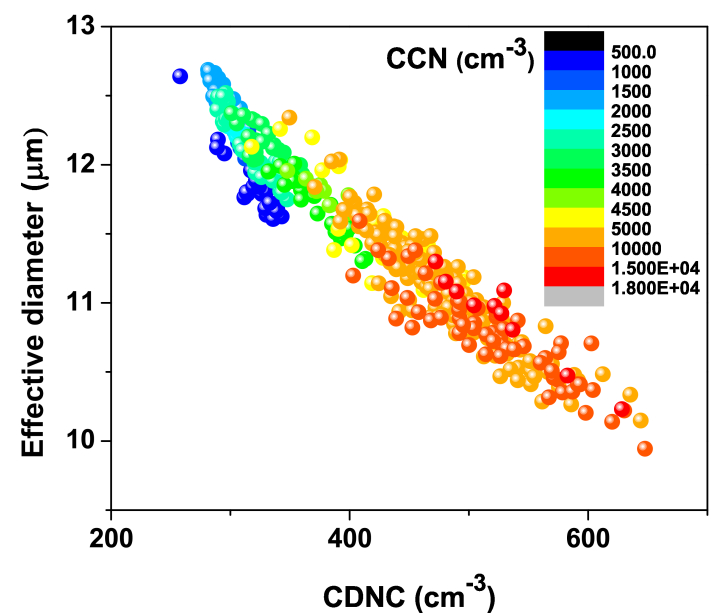

Figure 1. Variation of cloud microphysical parameters (droplet number concentration and effective diameter) with $\mathrm{CCN}$ number concentration.

of cloud droplets. At the same time higher droplet number regime has a smaller effective droplet diameter. For estimating AIE, CCN concentration, cloud droplet number concentration, and droplet effective diameter at different liquid water contents were examined. Figure 2 depicts the relation between the cloud microphysical parameters, CDNC, ED, and LWC. It clearly shows the reduction in the ED with increase in CDNC for all LWC values. Sharing the same available liquid water content by more cloud droplets leads to reduction in its size.

\subsection{AIE estimation from droplet effective diameter and number concentration}

It is to be noted that the correlations between $\mathrm{CCN}$ and CDNC as well as between CCN and $R_{\text {eff }}$ are statistically significant for all LWC bins considered in this study. The significant test for CCN versus CDNC and CCN versus $R_{\text {eff }}$ for different LWC bins is found to be statistically significant with a strong confidence level. Figure 3 a shows the variation of $\mathrm{CDNC}$ with $\mathrm{CCN}$ concentration for three different narrow LWC bins of $0.20,0.21$, and $0.22 \mathrm{~g} \mathrm{~m}^{-3}$. It shows an increase in CDNC with an increase in $\mathrm{CCN}$ concentration. The value exponents of power law fit between $\mathrm{CDNC}$ and $\mathrm{CCN}$ were $0.24,0.23$, and 0.22 . This results in $\mathrm{AIE}_{\mathrm{n}}$ estimates of 0.08 , 0.076 , and 0.074 respectively.

Analysis of the variation of $R_{\text {eff }}$ with CCN concentration (Fig. 3b) shows the reduction in $R_{\text {eff }}$ with an increase in CCN concentration. The linear fit to the log-log plot of $R_{\text {eff }}$ and CCN shows a good correlation for each individual LWC bin where the value of exponent $\left(\mathrm{AIE}_{\mathrm{s}}\right)$ varies as $-0.055,-0.051$, and -0.050 , respectively, for LWC bins of $0.20,0.21$, and $0.22 \mathrm{~g} \mathrm{~m}^{-3}$. From this, it is clear that increased CCN concentration led to a larger number of cloud droplets of smaller size, which is generally termed aerosol

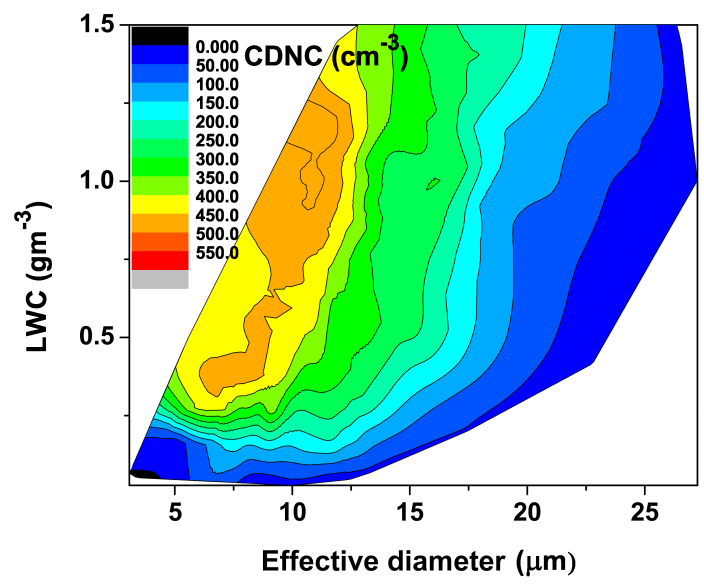

Figure 2. The contour plot shows the relationship between cloud microphysical parameters, cloud droplet number concentration (CDNC), droplet effective diameter (ED), and LWC. ED decreases with increase in CDNC for all LWCs.

indirect effect, represented herein by $\mathrm{AIE}_{\mathrm{s}}$. It can be noted that $\mathrm{AIE}_{\mathrm{n}}$ values are about 30-40\% higher than $\mathrm{AIE}_{\mathrm{s}}$. This clearly suggests that the overestimate of $\mathrm{AIE}_{\mathrm{n}}$ may be due to some other effects such as dispersion and entrainment. Some of the previous investigations of $\mathrm{AIE}_{\mathrm{n}}$ using aircraft measurements generally relate sub-cloud aerosol measurements with in-cloud droplet number concentrations without grouping it into constant LWC bins and attributed the overestimation to entrainment mixing processes (Shao and Liu, 2009). The systematic discrepancy between $\mathrm{AIE}_{n}$ and $\mathrm{AIE}_{\mathrm{s}}$ is caused primarily by the differential loss of cloud liquid water between clean and polluted clouds (Shao and Liu, 2006). Previous studies have also shown that droplet dispersion effect can partly offset the Twomey cooling effect. However, there is no clear demonstration of observed differences between $\mathrm{AIE}_{\mathrm{n}}$ and $\mathrm{AIE}_{\mathrm{s}}$. This warrants a study on why $\mathrm{AIE}_{\mathrm{n}}$ overestimates $\mathrm{AIE}_{\mathrm{s}}$. This study clearly provides an observational demonstration of overestimation of $\mathrm{AIE}_{\mathrm{n}}$ as compared to $\mathrm{AIE}_{\mathrm{S}}$ and how the droplet dispersion effect offset brings down the $\mathrm{AIE}_{\mathrm{n}}$ close to $\mathrm{AIE}_{\mathrm{s}}$.

We have analysed the LWC variation of non-precipitating clouds for the period considered in this analysis, which is presented in Fig. 4 as a frequency distribution of LWC. It can be seen that it is varied from 0 to $1 \mathrm{~g} \mathrm{~m}^{-3}$ with a maximum percentage occurrence between 0.05 and $0.5 \mathrm{~g} \mathrm{~m}^{-3}$. Thus considering this, aerosol indirect effect in terms of number concentration and droplet size has been calculated for each bin of liquid water content. From Fig. 5, it is observed that beyond $0.35 \mathrm{~g} \mathrm{~m}^{-3}$ of LWC, the variability of the values seems to be high due to less availability of data and lower statistical significance, which is separated by a dotted line in the figure. For this AIE analysis, $\mathrm{CCN}$ and cloud microphysical properties (CDNC, $R_{\text {eff }}$ ) were first grouped for different LWCs, and a bin interval of $0.01 \mathrm{~g} \mathrm{~m}^{-3}$ was selected. In 

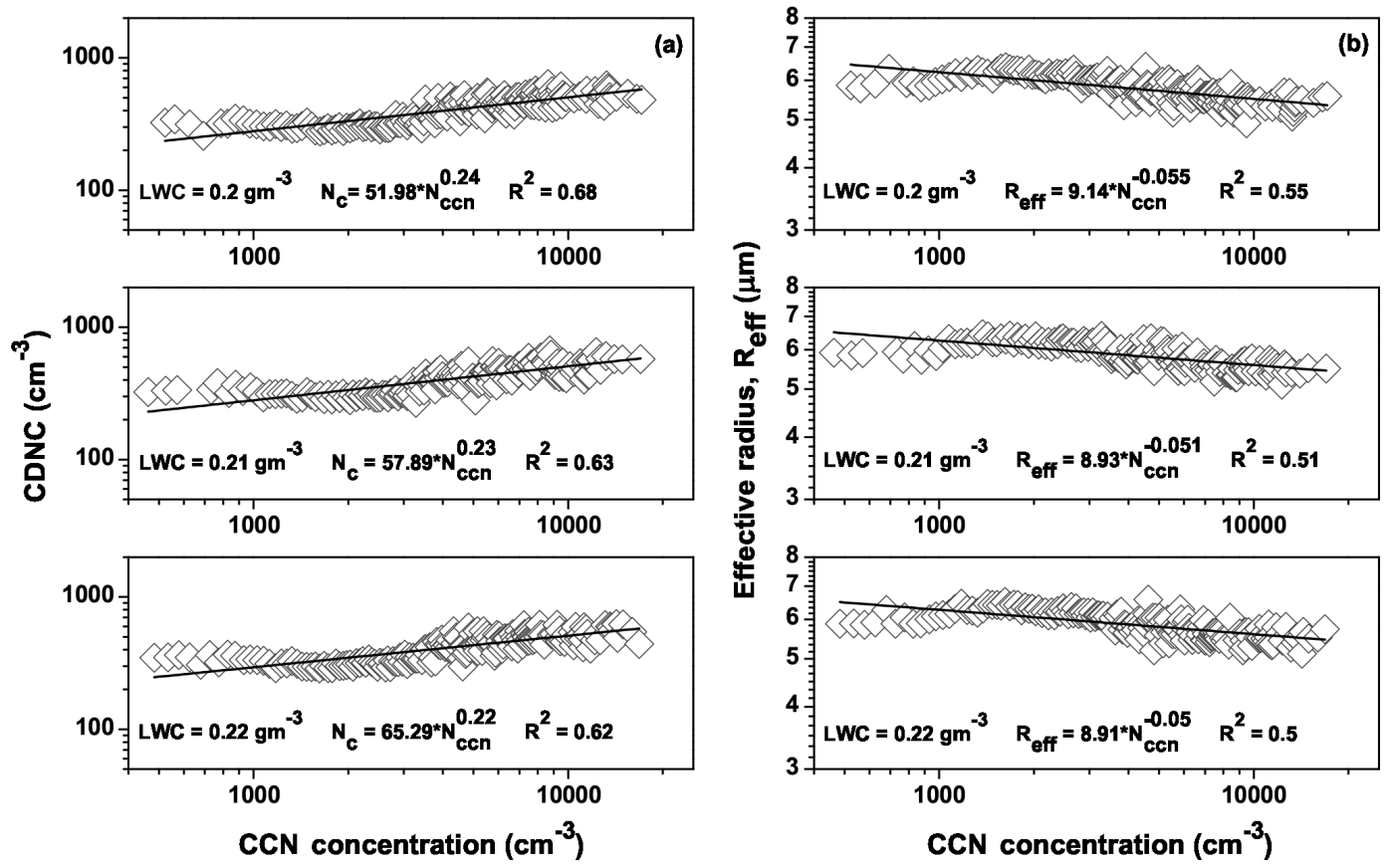

Figure 3. Scatter plot showing relation between cloud condensation nuclei $(\mathrm{CCN})$ concentration measured at $0.6 \%$ supersaturation and cloud droplet number concentration (CDNC) and CCN concentration versus cloud effective radius $\left(R_{\text {eff }}\right)$ for three LWC bins $(0.20,0.21$, and $0.22 \mathrm{~g} \mathrm{~m}^{-3}$ ).

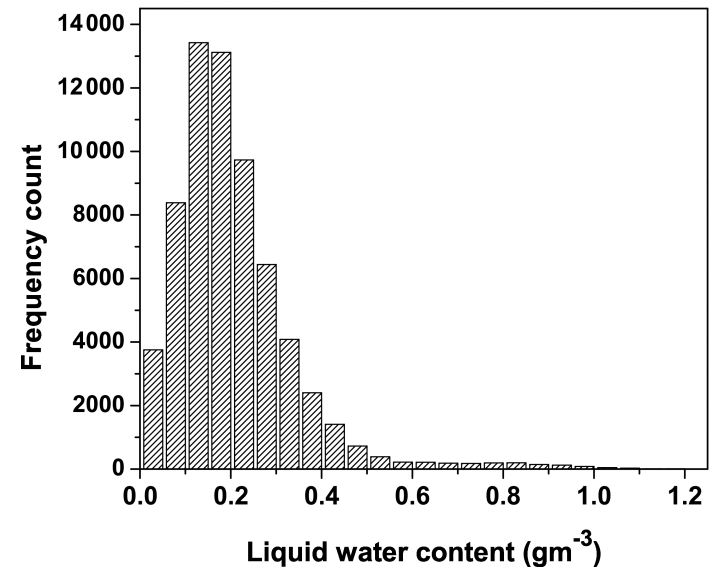

Figure 4. Frequency distribution plot of the measured LWC.

Fig. 5, the aerosol indirect effect and dispersion factor for the mentioned LWC ranges are represented, in which the green line corresponds to $\mathrm{AIE}_{\mathrm{s}}$, the black line to $\mathrm{AIE}_{\mathrm{n}}$, and the blue line to dispersion factor.

The estimated AIE shows its maximum value at lower LWC regime, reduced to half in the moderate LWC regime, and falls to a minimum at higher LWC range. In this observation, the maximum AIE estimated from droplet concentration and size is $0.103\left(\mathrm{AIE}_{\mathrm{n}}\right)$ and $0.088\left(\mathrm{AIE}_{\mathrm{s}}\right)$. Pandithurai et al. (2012), using CAIPEEX aircraft data, reported AIE over India from both methods is found to be $0.13\left(\mathrm{AIE}_{\mathrm{n}}\right)$ and

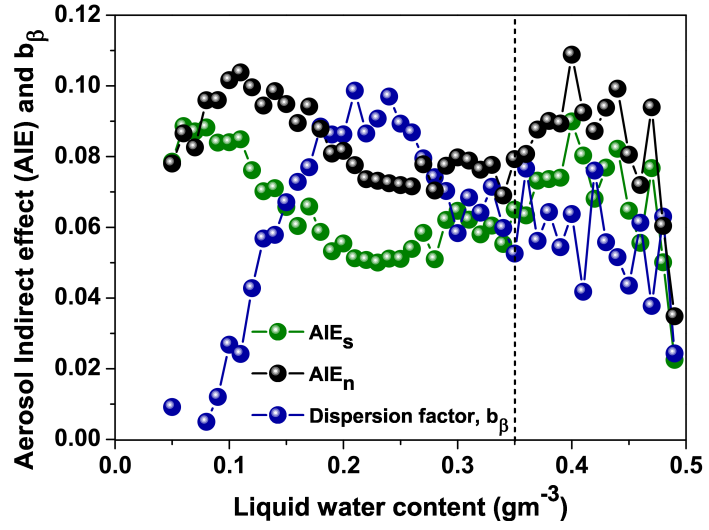

Figure 5. Aerosol indirect effect estimates using $\mathrm{AIE}_{\mathrm{n}}, \mathrm{AIE}_{\mathrm{s}}$, and the dispersion factor for the LWC ranges are represented. Green, black, and blue lines correspond to $\mathrm{AIE}_{\mathrm{S}}, \mathrm{AIE}_{\mathrm{n}}$, and dispersion factor respectively.

$0.07\left(\mathrm{AIE}_{\mathrm{s}}\right)$. In the lower LWC regime, reduced collisioncoalescence may cause a large number of smaller droplets with almost same size, which increases the AIE and reduces the dispersion factor.

\subsection{Dispersion effect}

It is well known from earlier studies that droplet relative dispersion $(\varepsilon)$ is an important cloud microphysical parameter, which is defined as the ratio of spectral width of cloud 

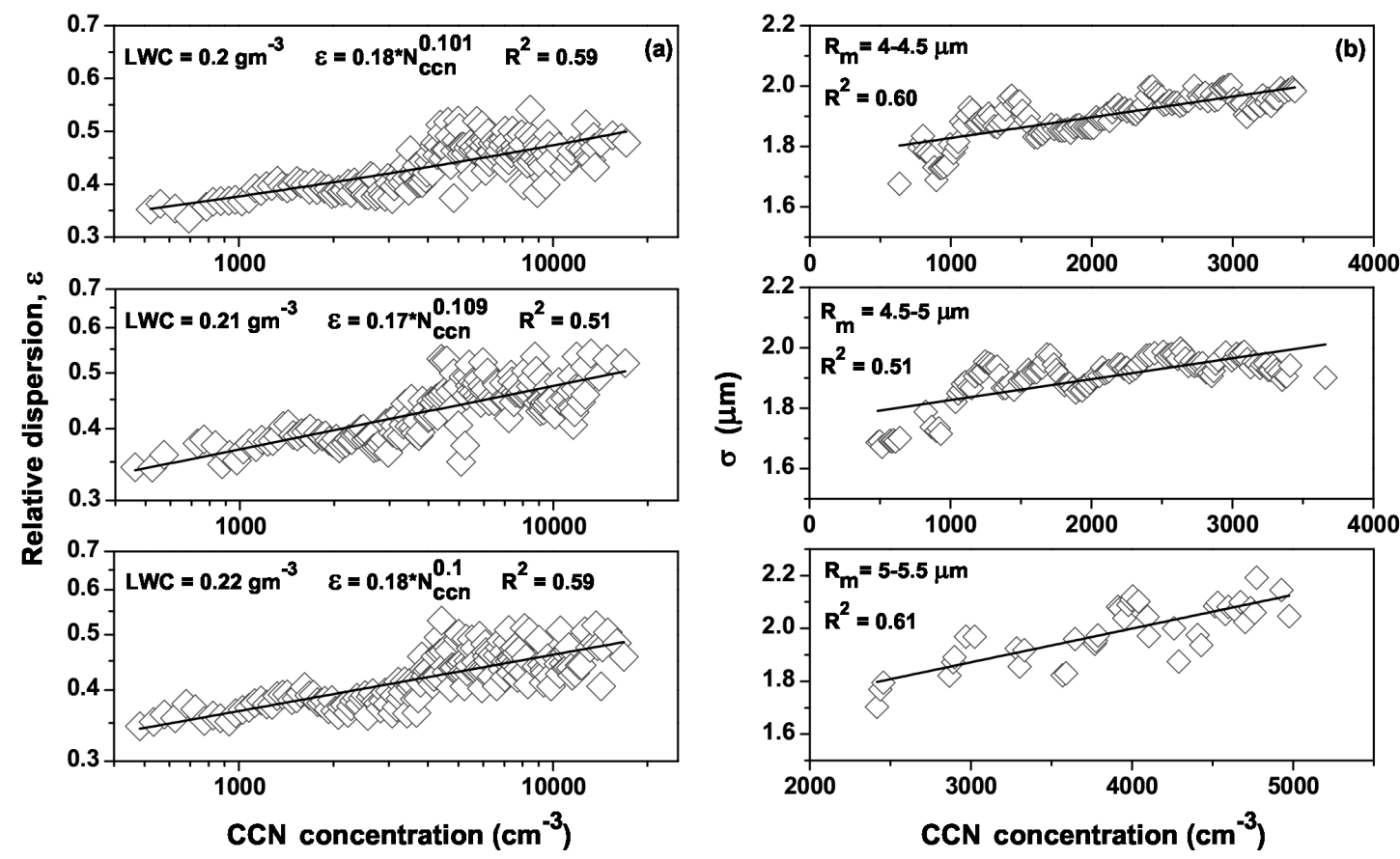

Figure 6. Scatter plots showing the changes in relative dispersion $(\varepsilon)$ and spectral width of cloud droplet $(\sigma)$ with CCN number concentration.

droplet size distribution $(\sigma)$ to mean radius $\left(r_{\mathrm{m}}\right)$. Liu and Daum (2002) noted that higher CCN concentration will cause broader cloud droplet spectra, which will reduce cloud albedo - thus tending to reduce the AIE. From Fig. 6a, it can be seen that the relative dispersion increases with $\mathrm{CCN}$ concentration, which is similar to previous studies (Liu and Daum, 2002; Pandithurai et al., 2012).

Apart from this, Fig. $6 \mathrm{~b}$ shows the observed variation of $\sigma$ with $\mathrm{CCN}$ concentration, for fixed mean radius for three narrow ranges 4-4.5, 4.5-5, and 5-5.5 $\mu \mathrm{m}$, in which $\sigma$ increases with $N_{\mathrm{ccn}}$. This observation is similar to that reported by previous investigators through aircraft measurements (Hudson and Yum, 1997; Miles et al., 2000; Pandithurai et al., 2012). Hudson and Yum (1997) demonstrated that standard deviation of cloud droplet spectra will be higher at higher CCN concentration from the ASTEX experiment of 1992. In general, clean maritime clouds have larger droplet size and larger $\sigma$, while polluted continental clouds have smaller drops with smaller $\sigma$. According to Yum and Hudson (2005), the large dispersion observed in the continental polluted cloud was possibly due to smaller droplets rather than broader droplet spectrum. From this observation, we can see that the increase in relative dispersion in polluted continental clouds is not only because of the reduction in droplet radius at higher $N_{\text {ccn }}$ but also due to increase in $\sigma$. According to Liu and Daum (2002), anthropogenic aerosols have a complex chemical composition, which leads to broader activated drop size distribution, and those small droplets in the cloud compete for water vapour and broaden the size spectrum.
Further, effective radius ratio, $\beta$, is an increasing function of relative dispersion, $\varepsilon$, of a cloud droplet. The value of $\beta$ varied from 1.06 to 1.28 . Similarly the value of $\varepsilon$ varied from 0.27 to 0.59 . Higher $\varepsilon$ corresponds to higher $\mathrm{CCN}$ concentration. Figure 7 shows the relation between water per droplet $(L / N)$ and effective radius ratio, $\beta$. It is found that $\beta$ decreases with $L / N$, and the linear fit to the data gives the following relation with a correlation coefficient of 0.73 . The dispersion factor estimated from whole data set is 0.07 . A value of $b_{\beta}=0.07$ indicates that the dispersion can offset AIE by $21 \%(3 \times 0.07)$.

\subsection{AIE estimation considering dispersion effect}

Earlier studies (Peng and Lohmann, 2003; Liu et al., 2008; Liu and Daum, 2002) have reported that the dispersion effect tends to offset the AIE in the range from 10 to $80 \%$. On the contrary, Martins and Silva Dias (2009) reported that the dispersion effect enhances the Twomey cooling for biomass burning aerosols in the dry region. Shao and Liu (2006) proposed that the real strength of the AIE should be the sum of the Twomey cooling effect and the compensating effects such as droplet dispersion effect. In most of the previous works, the AIE is calculated mainly by one of the following methods: either aerosol versus cloud droplet number or aerosol versus $R_{\text {eff. }}$ A few studies have reported that accurate representation of AIE needs to consider (i) the dispersion effect and (ii) entrainment effects. In this study, we present both the methods and systematic difference, which can be minimized by considering the dispersion effect. From this study, 


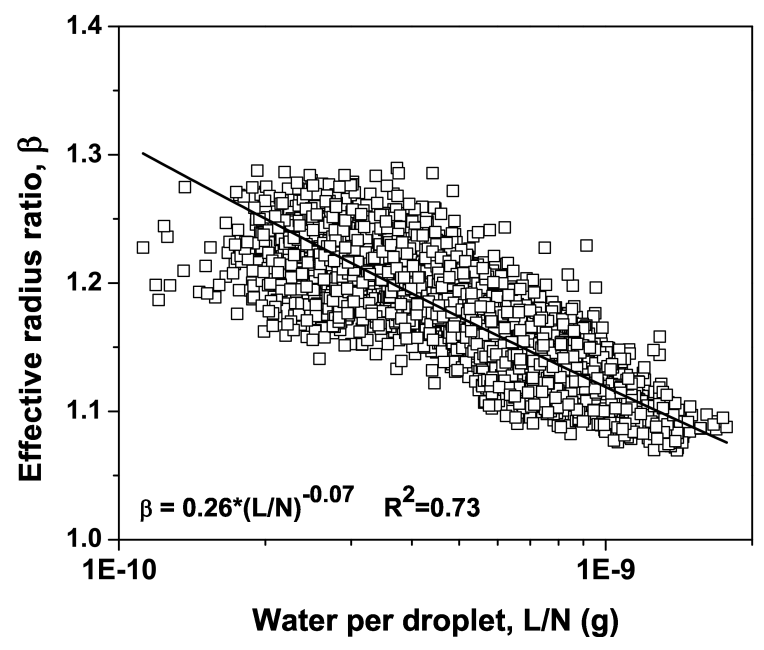

Figure 7. Scatter plot between water per droplet $(L / N)$ and effective radius ratio $(\beta)$.

the maximum dispersion factor $b_{\beta}$ is found to be 0.098 for LWC of $0.21 \mathrm{~g} \mathrm{~m}^{-3}$. The corresponding AIE $\mathrm{n}_{\mathrm{n}}$ was 0.077 , and the dispersion effect is found to be -0.023 , which can offset the $\mathrm{AIE}_{\mathrm{n}}$ effect by $29.6 \%$. Therefore, the resultant $\mathrm{AIE}_{\mathrm{n}}$ is $0.054(0.077-0.023)$. This resultant $\mathrm{AIE}_{\mathrm{n}}$ is close to the estimated $\mathrm{AIE}_{\mathrm{S}}(0.051)$ using $R_{\text {eff }}$ for the same LWC bin. From this, we can clearly state that dispersion effect is implicitly included in the estimation of $\mathrm{AIE}_{\mathrm{s}}$. This analysis is presented in Fig. 8, which shows the variation of $\mathrm{AIE}_{\mathrm{s}}$ and resultant $\mathrm{AIE}_{\mathrm{n}}$, i.e. $\mathrm{AIE}_{\mathrm{n}}+$ dispersion effect for different $\mathrm{LWC}$ regimes along with dispersion offset in percentage. The dispersion effect is much less at lower LWC regimes where AIE has its maximum value and tends to increase with LWC; it shows a maximum at moderate $\mathrm{LWC}$ regime and then found to reduce at higher LWC regimes. From the figure we can see that resultant $\mathrm{AIE}_{\mathrm{n}}$ closely agrees with $\mathrm{AIE}_{\mathrm{s}}$ for all LWC range except in the lower LWC where the dispersion effect is too small, and the AIE has its maximum value.

\section{Summary and conclusion}

Aerosol indirect and dispersion effects on monsoon clouds over a high-altitude site in Western Ghats using in situ instruments were studied. Advantage of simultaneous measurement of aerosol and cloud microphysical properties have been utilized from this observatory and studied (i) discrepancy between aerosol indirect effect estimates from different methods, (ii) the variation in albedo susceptibility with LWC, and (iii) the dispersion effect variation with LWC and the resultant AIE. Over the Indian subcontinent, the relative dispersion is found to increase with aerosol concentration in continental clouds sampled through aircraft measurements over several regions during the CAIPEEX experiment (Pandithurai et al., 2012; Prabha et al., 2012). Higher concentration

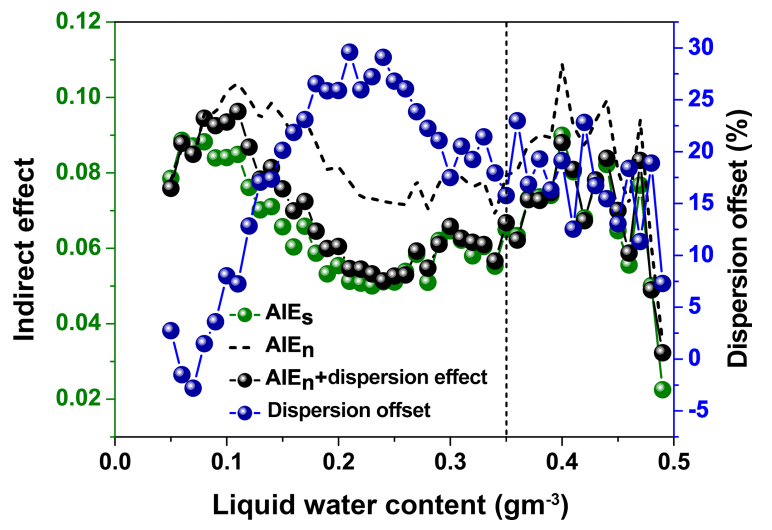

Figure 8. Aerosol indirect effect estimated after considering dispersion effect in $\mathrm{AIE}_{\mathrm{n}}$ : left axis represents AIE; right axis represents dispersion offset in percentage.

of anthropogenic aerosols with different chemical composition and sources can contribute to cloud droplets of different sizes. An increase in spectral width of the drop size distribution $(\sigma)$ with $N_{\text {ccn }}$ for a given mean cloud droplet radius was also observed, indicating a broader spectrum at high aerosol concentration. As Liu and Daum (2002) suggested, this increasing tendency of $\sigma$, and hence $\varepsilon$, might be because of several possible reasons, such as mixing of clouds at different developmental stages, or it may be due to strong collisioncoalescence.

The AIE is found to be maximum in low liquid water content clouds, but at the same time dispersion of cloud droplet size distribution is much less. While considering clouds with moderate liquid water content we can see an increase in dispersion effect, which offsets the AIE. At higher LWC, the dispersion as well as AIE is found to be decreased. In this study, we investigated the effect of aerosol on cloud effective radius and droplet number concentration. The maximum aerosol indirect effect derived from relative changes in cloud droplet effective radius $\left(\mathrm{AIE}_{\mathrm{S}}\right)$ and relative changes in cloud droplet concentration $\left(\mathrm{AIE}_{\mathrm{n}}\right)$ with respect to relative changes in aerosol were found to be 0.088 and 0.103 , respectively, with a maximum dispersion offset of $29.6 \%$. From the resultant $\mathrm{AIE}_{\mathrm{n}}$, it is clear that in AIE estimate using droplet concentration, the dispersion effect should be taken into account for correct estimation of AIE. It is also confirmed that AIE estimation from effective droplet radius implicitly includes the dispersion effect. As the droplet effective radius is a ratio of third and second moment of DSD, the dispersion in DSD is implicitly included; hence the AIE estimates obtained through relative changes in observed $R_{\text {eff }}$ do not need to correct for the dispersion effect. 


\section{Data availability}

The data used in this study are from the data repository of HACPL, part of IITM, Pune. The data used in this study can be found in the following link: http://www.tropmet.res. in/ majfiles/acp-16-1-2016.html.

Acknowledgements. Authors are grateful to all the team members of High Altitude Cloud Physics Laboratory (HACPL) of IITM. HACPL is fully funded by Ministry of Earth Sciences (MoES), Government of India, New Delhi. The data used in this study are from the data repository of HACPL, part of IITM, Pune. Authors are thankful to the director of IITM for his support and encouragement. Authors would like to thank two anonymous reviewers for constructive comments, which helped in improving the manuscript.

Edited by: J. P. Huang

\section{References}

Bower, K. N., Choularton, T. W., Latham, J., Nelson, J., Baker, M. N., and Jensen, J.: A parameterization of warm clouds for use in atmospheric general circulation models, J. Atmos. Sci., 51, 2722-2732, doi:10.1175/15200469(1994)051<2722:APOWCF>2.0.CO;2, 1994.

Feingold, G., Eberhard, W., Lane, D. E., and Previdi, M.: First measurements of the Twomey effect using groundbased remote sensors, Geophys. Res. Lett., 30, 1287, doi:10.1029/2002GL016633, 2003.

Hansen, J. E. and Travis, L. D.: Light scattering in planetary atmospheres, Space Sci., 16, 527-610, doi:10.1007/BF00168069, 1974.

Huang, J., Wang, T., Wang, W., Li, Z., and Yan, H.: Climate effects of dust aerosols over East Asian arid and semiarid regions, J. Geophys. Res. Atmos., 119, 11398-11416, doi:10.1002/2014JD021796, 2014.

Hudson, J. G. and Yum, S. S.: Droplet spectral broadening in marine stratus, J. Atmos. Sci., 54, 2642-2654, doi:10.1175/1520469(1997)054<2642:DSBIMS>2.0.CO;2, 1997.

Hudson, J. G. and Noble, S.: Response to Comment on "Cloud Droplet Spectral Width Relationship to CCN Spectra and Vertical Velocity" of Yangang Liu, Peter H. Daum and Chunsong Lu, J. Geophys. Res., 119, 1878-1882, doi:10.1002/2013JD020559, 2013.

Leena, P. P., Pandithurai, G., Anil kumar, V., Murugavel, P., Sonbawne, S. M. and Dani, K. K.: Seasonal variability in aerosol, $\mathrm{CCN}$ and their relationship observed at a high-altitude site in Western Ghats, Meteorol. Atmos. Phys., 128, 143-153, doi:10.1007/s00703-015-0406-0, 2016.

Liu, Y. and Daum, P. H.: Spectral dispersion of cloud droplet size distributions and the parameterization of cloud droplet effective radius, Geophys. Res. Lett., 27, 1903-1906, doi:10.1029/1999GL011011, 2000.
Liu, Y. and Daum, P. H.: Indirect warming effect from dispersion forcing, Nature, 419, 580-581, doi:10.1038/419580a, 2002.

Liu, Y., Daum, P. H., and Yum, S. S.: Analytical expression for the relative dispersion of the cloud droplet size distribution, Geophys. Res. Lett., 33, L02810, doi:10.1029/2005GL024052, 2006.

Liu, Y., Daum, P. H., Guo, H., and Peng, Y.: Dispersion bias, dispersion effect and the aerosol-cloud conundrum, Environ. Res. Lett., 3, 045021, doi:10.1088/1748-9326/3/4/045021, 2008.

Liu, Y., Daum, P. H., and Lu, C.: Comment on "Cloud Droplet Spectral Width Relationship to CCN Spectra and Vertical Velocity" by Hudson et al, J. Geophys. Res., 119, 1874-1877, doi:10.1002/2012JD019207, 2013.

Martins, J. A. and Silva Dias, M. A. F.: The impact of smoke from forest fires on the spectral dispersion of cloud droplet size distributions in the Amazonian region, Environ. Res. Lett., 4, 015002, doi:10.1088/1748-9326/4/1/015002, 2009.

Menon, S., Del Genio, A. D., Kaufman, Y., Bennartz, R., Koch, D., Loeb, N., and Orlikowski D.: Analyzing signatures of aerosolcloud interactions from satellite retrievals and the GISS GCM to constrain the aerosol indirect effect, J. Geophys. Res., 113, D14S22, doi:10.1029/2007JD009442, 2008.

Miles, N. L., Verlinde, J., and Clothiaux, E. E.: Cloud droplet size distributions in low-level stratiform clouds, J. Atmos. Sci., 57, 295-311, doi:10.1175/15200469(2000)057<0295:CDSDIL>2.0.CO;2, 2000.

Pandithurai, G., Dipu, S., Prabha Thara, V., Maheskumar, R. S., Kulkarni, J. R., and Goswami, B. N.: Aerosol effect on droplet spectral dispersion in warm continental cumuli, J. Geophys. Res., 117, D16202, doi:10.1029/2011JD016532, 2012.

Peng, Y. and Lohmann, U.: Sensitivity study of spectral dispersion of the cloud droplet size distribution on the indirect aerosol effect, Geophys. Res. Lett., 30, 1507, doi:10.1029/2003GL017192, 2003.

Prabha, T. V., Patade, S., Pandithurai, G., Khain, A., Axisa, D., Pradeep Kumar, P., Maheskumar, R. S., Kulkarni, J. R., and Goswami, B. N.: Spectral width of premonsoon and monsoon clouds over Indo-Gangetic valley, J. Geophys. Res., 117, D20205, doi:10.1029/2011JD016837, 2012.

Roberts, G. and Nenes, A.: Continuous-flow stream wise thermal gradient CCN chamber for airborne measurements, Aerosol Sci. Tech., 39, 206-221, doi:10.1080/027868290913988, 2005.

Shao, H. and Liu, G.: Influence of mixing on evaluation of the aerosol first indirect effect, Geophys. Res. Lett., 33, L14809, doi:10.1029/2006GL026021, 2006.

Shao, H. and Liu, G.: A critical examination of the first aerosol indirect effect, J. Atmos. Sci., 66, 1018-1032, doi:10.1175/2008JAS2812.1, 2009.

Slingo, A.: Sensitivity of Earth's radiation budget to changes in low clouds, Nature, 343, 49-51, doi:10.1038/343049a0, 1990.

Twomey, S.: Pollution and the planetary albedo, Atmos. Environ., 8, 1251-1256, doi:10.1016/0004-6981(74)90004-3, 1974.

Yum, S. S. and Hudson, J. G.: Adiabatic predictions and observations of cloud droplet spectral broadness, J. Atmos. Res., 73, 203-223, doi:10.1016/j.atmosres.2004.10.006, 2005. 